\title{
Penguatan Keterampilan Penilaian Autentik Guru IPA Biologi di Kabupaten Bogor
}

\author{
Rizhal Hendi Ristanto, Refirman Djamahar \\ Pendidikan Biologi, Fakultas Matematika dan Ilmu Pengetahuan Alam, Universitas \\ Negeri Jakarta \\ Jl. Rawamangun Muka, Jakarta Timur, DKI Jakarta \\ Email: rizhalhendi@unj.ac.id
}

\begin{abstract}
Measurement of students' process skills in science lessons by teachers can be applied through an authentic assessment process. This valuation method is by what was mandated in the 2013 curriculum. The problem related to the implementation of authentic assessment by Biology Science teachers in Bogor Regency is that teachers are less skilled in applying authentic assessment in the learning process. This service activity aims to ensure that teachers not only understand but are also trained in using authentic assessment well. The target of this service activity is science teachers who are members of the Subject Teachers' Consultation (MGMP) in Bogor Regency. The teacher involved in this activity amounted to 40 people consisting of various Schools in Bogor Regency. The action was held at SMPN 1 Cibinong, Bogor in August 2018. The instruments for implementing community service included test instruments and questionnaires. The implementation of this service includes several stages, namely 1) pre-test and observation, 2) socialization of understanding, forms and examples of authentic assessment, 3) practice of developing and compiling authentic assessments, 4) presentation of results and 5) posttest. The results of the activity showed that there were differences in the score scores of the understanding of the teacher's authentic assessment concept on the pretest and posttest. The average score of the pretest is classified as very low at 20.06 , and the post-test mean score is 68.75 in the sufficient category. It can be concluded that the discussing about authentic assessments can be well received by teachers in the Subject of Teacher Subjects in the Bogor.
\end{abstract}

Keywords: Authentic assessment, Bogor, science, teacher.

Abstrak
Pengukuran keterampilan proses peserta didik pada matapelajaran IPA oleh
guru dapat diterapkan melalui proses penilaian autentik. Metode penilaian ini
sesuai dengan yang diamanatkan pada kurikulum 2013. Permasalahan terkait
implementasi penilaian autentik oleh guru IPA Biologi di Kabupaten Bogor
adalah guru kurang terampil dalam menerapkan penilaian autentik pada proses
pembelajaran. Kegiatan pengabdian ini bertujuan supaya guru tidak hanya
memahami tetapi juga terampil dalam menerapkan penilaian auntentik dengan


Rizhal Hendi Ristanto, Refirman Djamahar

baik. Sasaran kegiatan pengabdian ini adalah guru IPA yang tergabung pada Musyawarah Guru Mata Pelajaran (MGMP) di Kabupaten Bogor. Guru yang dilibatkan pada kegiatan ini berjumlah 40 orang yang terdiri dari berbagai Sekolah yang terdapat di Kabupaten Bogor. Kegiatan dilaksanakan di SMPN 1 Cibinong, Kabupaten Bogor pada Bulan Agustus 2018. Instrumen pelaksanaan pengabdian kepada masyarakat mencakup instrumen tes dan angket. Pelaksanaan kegiatan pengabdian ini meliputi beberapa tahapan yaitu 1) pre test dan observasi, 2) Sosialisasi tentang pengertian, bentuk dan contoh penilaian autentik, 3) praktik mengembangkan dan menyusun penilaian autentik, 4) presentasi hasil, dan 5) postes. Hasil kegiatan menunjukkan bahwa terdapat perbedaan skor nilai pemahaman konsep penilaian autentik guru pada pretes dan postes. Skor rata-rata pretes adalah tergolong sangat rendah yaitu 20,06 dan skor rerata postes adalah 68,75 pada kategori cukup. Hal ini dapat disimpulkan bahwa penyapaian informasi terhadap penilaian autentik dapat diterima baik oleh guru Musyawarah Guru Mata Pelajaran (MGMP) IPA Kabupaten Bogor.

Kata kunci: Bogor, guru, ipa, penilaian autentik.

\section{PENDAHULUAN}

Berdasarkan Undang-Undang nomor 20 tahun 2003 tentang Sistem Pendidikan Nasional menyatakan bahwa pendidikan adalah usaha sadar dan terencana untuk mewujudkan suasana belajar dan proses pembelajaran agar peserta didik secara aktif mengembangkan potensi dirinya untuk memiliki kekuatan spiritual keagamaan, pengendalian diri, kepribadian, kecerdasan, akhlaq mulia, serta keterampilan yang diperlukan dirinya, masyarakat, bangsa, dan Negara. Hal ini dapat diartikan sebagai suatu proses pendidikan yang terencana diarahkan untuk mewujudkan suasana belajar dan proses pembelajaran. Penerapan pendidikan yang baik akan mengutamakan keterampilan pada proses belajar peserta didik (Arif, 2014). Pengukuran keterampilan proses peserta didik oleh guru dapat diterapkan melalui proses penilaian autentik.

Penilaian autentik dapat diartikan sebagai suatu penilaian yang memadukan antara kesiapan peserta didik, proses, dan hasil belajar (Arif, 2014; Kunandar, 2014). Keterpaduan ketiga komponen sehingga dapat menggambarkan kapasitas, gaya, dan perolehan belajar peserta didik atau bahkan mampu menghasilkan dampak instruksional dan dampak pengiring dari kegiatan pembelajaran. Hasil penilaian autentik dapat dijadikan dasar oleh guru untuk merencanakan program kegiatan lanjutan seperti perbaikan (remedial), pengayaan (enrichment), atau pelayanan konseling. Bentuk penerapan penilaian autentik juga dapat digunakan sebagai bahan untuk memperbaiki proses pembelajaran sesuai dengan standar penilaian pendidikan (Larkin, 2014; Ngadip, 2010; Swacker, 2003).

Kegiatan peningkatan kompetensi guru setalah implementasi kurikulum 2013 terkait pedagogik telah banyak dilakkan (Amin, Bain, \& Suryadi, 2016; Nurjananto \& Kusumo, 2015; Safitri \& Oktavia, 2017). Salah satu keterampilan guru untuk menerapkan kurikulum adalah penilaian autentik (Djamahar, Ristanto, Sartono, Ichsan, \& Muhlisin, 2018; Safitri \& Oktavia, 2017; Wangid, Mustadi, Senen, \& Herianingtyas, 2018). Penilaian autentik merupakan suatu metode penilaian yang dilakukan kepada guru yang mencakup pada ranah kognitif, afektif dan psikomotor (Astriyandi, 
Chotimah, \& Faisal, 2016; Siswanto, Saptaningrum, Saefan, Patonah, \& Nuvitalia, 2015). Hasil studi menunjukkan bahwa guru masih kesulitan dalam menerapkan penilaian autentik dengan tepat (Astriyandi et al., 2016; Sridharan \& Mustard, 2016).

Kegiatan evaluasi dalam proses pembelajaran biologi kepada peserta didik merupakan suatu kewajiban oleh guru. (Astriyandi et al., 2016). Kegiatan menilai peserta didik selama proses belajar biologi meliputi proses dan hasil belajar dengan menerapkan prinsip ketuntasan belajar secara berkesinambungan (Frey, Schmitt, \& Allen, 2012). Berdasrkan jenisnya, evaluasi hasil belajar pada satuan pendidikan mencakup penilaian kelas, ujian akhir, test kemampuan dasar dan penilaian mutu (Afrianto, 2019; Delita, 2018). Evaluasi proses pembelajaran biologi kepada peserta didik dapat dilakukan secara berkala, menyeluruh, transparan, dan sistemik untuk mencapai standar kompetensi tertentu. (Komalasari, 2011; Wangid et al., 2018)

Implementasi kurikulum 2013 menemukan berbagai kendala (Delita, 2018; Hobma, Ram, Muijtjens, Grol, \& Van Der Vleuten, 2004; Ngadip, 2010; Safitri \& Oktavia, 2017). Kendala tersebut meliputi teknik evaluasi yang dilakukan oleh guru harus bersifat nyata dan autentik, kesulitan penerapan scientific approach pada proses pembelajaran dan kesulitan mengembangkan proses pembelajaran yang dapat membuat siswa aktif (Djamahar et al., 2018; Zuriyani, 2010). Penilaian autentik penting diterapkan pada proses pembelajaran biologi agar peserta didik dapat dibimbing untuk tidak hanya memiliki kemampuan pada bidang pengetahuan saja, tetapi juga sikap dan keterampilan (Satrianawati, 2014). Tuntutan pada kurikulum 2013 salah satunya adalah penilaian autentik (Kusmana, 2017; Lestari, Mertha, \& Kusmiyati, 2019). Setelah diberlakukan kurikulum 2013 maka penilaian autentik dianggap sebagai penilaian yang tepat dalam menilai hasil belajar peserta didik (Kuntari, 2013). Hal tersebut sesuai dengan Permendikbud No. 104 tahun 2014 pasal 2 ayat 2 yang menyebutkan bahwa penilaian autentik merupakan pendekatan utama dalam penilaian hasil belajar peserta didik oleh pendidik.

Penilaian autentik difenisikan sebagai suatu proses pengumpulan informasi yang dilakukan oleh guru untuk memantau perkembangan dan pencapaian pembelajaran peserta didik(Jerez, Baloian, \& Zurita, 2017; Plake \& Impara, 1996). Kegiatan tersebut dilakukan melalui berbagai teknik yang mampu mengungkapkan, membuktikan, atau menunjukkan secara tepat bahwa tujuan pembelajaran telah benarbenar dikuasai dan dicapai (Nurjananto \& Kusumo, 2015). Penilaian autentik tidak hanya menekankan aspek kognitif saja, melainkan juga aspek afektif dan psikomotor (Afrianto, 2019; Djamahar et al., 2018). Permasalahan terkait implementasi penilaian autentik oleh guru IPA Biologi di Kabupaten Bogor adalah guru IPA masih kurang terampil dalam menerapkan penilaian autentik pada proses pembelajaran (Amin et al., 2016; Astriyandi et al., 2016; Satrianawati, 2014). Minimnya pemahaman guru IPA Biologi dalam terhadap bentuk penilaian autentik (Lestari et al., 2019; Siswanto et al., 2015). Hasil observasi menyebutkan bahwa guru masih kesulitan dalam melaksanakan penilaian autentik dengan prosedur yang benar dan lebih memilih menggunakan evaluasi pembelajaran secara konvensional. Kondisi tersebut dikarenakan belum intensifnya kegiatan yang mendukung guru dalam memberdayakan keterampilan menerapkan keterampilan autentik. Oleh karena itu diperlukan adanya kegiatan diskusi kepada guru-guru IPA Biologi di Kabupaten Bogor tentang berbagai dimensi 
pengetahuan dan praktik penilaian autentik. Harapannya, melalui diskusi dan pelatihan tersebut guru IPA Biologi di Kabupaten Bogor memahami dan terampil dalam kegiatan mengavaluasi pembelajaran IPA Biologi.

Peningkatan pemahaman dan keterampilan guru IPA Biologi di Kabupaten Bogor tentang dimensi penilaian autentik sesuai yang diamanatkan pada kurikulum 2013 perlu diberdayakan melalui kegiatan diskusi dan pelatihan. Kegiatan tersebut bertujuan supaya guru tidak hanya memahami tetapi juga semakin terampil dalam menerapkan penilaian auntentik dengan baik. Sehingga pencapaian belajar IPA Biologi oleh peserta didik benar mencerminkan hasil belajarnya. Penilaian autentik diyakini sebagai salah satu model penilaian terhadap peserta didik yang objektif, metode ini tidak hanya sekadar simbol, angka dan huruf, melainkan dapat mendeskripsikan kemampuan peserta didik dalam belajar IPA biologi secara nyata. Tujuan dari kegiatan ini adalah guru IPA Biologi di Kabupaten Bogor secara umum adalah guru mampu memahami dan terampil dalam menerapkan penilaian autentik pada mata pelajaran IPA Biologi di kelas.

\section{METODE}

Sasaran kegiatan pengabdian ini adalah guru IPA yang tergabung pada Musyawarah Guru Mata Pelajaran (MGMP) di Kabupaten Bogor. Kegiatan dialaksanakan di SMPN 1 Cibinong, Kabupaten Bogor pada Bulan Agustus 2018. Guru yang dilibatkan pada kegiatan ini berjumlah 40 orang yang terdiri dari berbagai Sekolah yang terdapat di Kabupaten Bogor. Terlaksananya kegiatan ini dengan memperhatikan beberapa hal berikut: 1) pemateri dipersyaratkan memiliki kompetensi teoritis dan praktis yang memadai dalam hal penilaian autentik, serta mampu mengimplementasikan pada proses pembalajaran, 2) persiapan pelaksanaan kegiatan PKM dilakukan secara menyeluruh, terutama yang berkaitan dengan materi kegiatan yang berupa: materi dan makalah tentang penilaian autentik; bentuk penilaian yang sesuai dan dengan penilaian autentik; media pembelajaran yang komunikatif dan menarik bagi peserta; materi kegiatan secara lengkap harus sudah diberikan kepada peserta kegiatan diawal sebelum kegiatan pengenalaan dan bimbingan teknis penilaian autentk dilaksanakan.

Instrumen pelaksanaan pengabdian kepada masyarakat mencakup instrumen tes dan angket. Pelaksanaan kegiatan pengabdian ini meliputi beberapa tahapan yaitu 1) pre test dan observasi, 2) Sosialisasi tentang pengertian, bentuk dan contoh penilaian autentik, 3) praktik mengembangkan dan menyusun penilaian autentik, 4) presentasi hasil, dan 5) postes.

\section{HASIL DAN PEMBAHASAN}

Pelaksananaan kegiatan pengabdian masyarakat diselenggarakan di SMP Negeri Cibinong, Kabupaten Bogor. Kegiatan pengabdian bekerjasama dengan MGMP IPA Kabupaten Bogor dengan dihadiri 40 guru matapelajaran IPA dari berbagai sekolah. Kegiatan dibuka oleh Kepala Dinas Pendidikan Kabupaten Bogor dan Kepala Sekolah SMPN 1 Cibinong. Tahap pertama dari pelaksanaan kegiatan pengabdian ini yaitu 
dengan memberikan pretes dan angket mengenai penilaian autentik kepada guru. Hasil dari angket terdapat pada Tabel 1 .

Tabel 1

Rangkuman hasil angket penilaian autentik

\begin{tabular}{|c|c|c|}
\hline No & Pertanyaan & Skor \\
\hline 1 & $\begin{array}{l}\text { Pelaporan hasil belajar IPA peserta didik saya selama ini selalu } \\
\text { memperhatikan proporsi yang jelas aspek pengetahuan, sikap dan } \\
\text { keterampilan }\end{array}$ & 37,5 \\
\hline 2 & $\begin{array}{l}\text { Penilaian prestasi belajar siswa, saya lakukan hanya melalui } \\
\text { ulangan harian, UTS dan UAS }\end{array}$ & 75,0 \\
\hline 3 & $\begin{array}{l}\text { Saya senantiasa mempersiapkan penilaian kepada peserta didik } \\
\text { dengan menyusun kisi-kisi dan rubrik penilaian }\end{array}$ & 43,8 \\
\hline 4 & Saya mengetahui prosedur dan berbagai macam penilaian autentik & 50,0 \\
\hline 5 & Saya sudah terbiasa menerapkan penilaian autentik kepada siswa & 45,0 \\
\hline 6 & $\begin{array}{l}\text { Saya memiliki pemahaman yang baik dalam mengevaluasi dan } \\
\text { menilai hasi belajar peserta didik }\end{array}$ & 52,5 \\
\hline 7 & Penilaian autentik perlu diterapkan dalam pembelajaran IPA & 87,5 \\
\hline 8 & $\begin{array}{l}\text { Selama ini saya telah menerapkan penilaian autentik, hal tersebut } \\
\text { memberatkan guru }\end{array}$ & 65,0 \\
\hline 9 & Penilaian autentik memberikan keadilan kepada peserta didik & 62,5 \\
\hline 10 & $\begin{array}{l}\text { Saya memahami pentingnya penilaian autentik pada pembelajaran } \\
\text { IPA, tetapi saya tidak melaksanakan metode tersebut }\end{array}$ & 75,0 \\
\hline
\end{tabular}

Berdasarkan hasil angket awal kepada guru IPA MGMP di Kabupaten Bogor dapat diambil beberapa kesimpulan yaitu 1) guru telah memahami pentingnya penilaian autentik dalam proses pembelajaran IPA, namun dominan guru tidak melaksanakan metode tersebut. 2) beberapa alasan guru tidak menerapkan penilaian autentik karena dianggap memberatkan. 3) guru merasa keberatan menerapkan pembelajaran autentik diasumsikan karena belum memahami prosedur penilaian autentik. 4) Guru IPA di Kabupaten Bogor belum terbiasa menerapkan penilaian autentik. Data skor pemahaman awal terkait konsep penilaian autentik terhadap guru di MGMP IPA di Kabupaten terdapat pada Tabel 2.

Tabel 2

Data skor pretes dan postes pemahaman konsep penilaian autentik

\begin{tabular}{lrr}
\hline Skor & Pretes & Postes \\
\hline Nilai min & 5,00 & 45,00 \\
Nilai max & 55,00 & 90,00 \\
Rerata & 20,06 & 68,75 \\
\hline
\end{tabular}

Berdasarkan Tabel 2 diketahui bahwa terjadi perbedaan skor nilai pemahaman konsep penilaian autentik guru pada pretes dan postes. Skor rata-rata pretes adalah tergolong sangat rendah yaitu 20,06 dan skor rerata postes adalah 68,75 pada kategori cukup. Hal ini dapaat disimpulkan bahwa penyapaian informasi terhadap penilaian autentik dapat diterima baik oleh guru MGMP IPA Kabupaten Bogor. 
Rizhal Hendi Ristanto, Refirman Djamahar

\section{PEMBAHASAN}

Pengabdian masyarakat merupakan suatu kegiatan bagian dari tri dharma perguruan tinggi. Kegiatan pengadian bertujuan untuk membantu masyarakat tertentu berupa tindakan nyata untuk membantu menyelesaikan masalah khususnya dalam mengembangkan kesejahteraan dan kemajuan bangsa Indonesia tanpa mengharapkan imbalan dalam bentuk apapun. Pengabdian kepada masyarakat merupakan pelaksanaan pengamalan ilmu pengetahuan, teknologi dan seni budaya langsung pada masyarakat secara kelembagaan melalui metodologi ilmiah sebagai penyebaran Tri Dharma Perguruan Tinggi serta tanggung jawab yang luhur dalam usaha mengembangkan kemampuan masyarakat, sehingga dapat mempercepat laju pertumbuhan tercapainya tujuan pembangunan nasional.

Salah satu upaya dalam mencapai tujuan tersebut dilaksanakan kegiatan pengabdian kepada masyarakat dengan tujuan peningkatan kompetensi guru dalam melaksanakan proses pembelajaran IPA di kelas. Kegiatan ini diterapkan penilaian autentik proses belajar siswa kepada guru IPA biologi di Kabupaten Bogor. Kegiatan ini memiliki tujun agar guru dapat melakukan pencanaan penilaian peserta didik sesuai dengan kompetensi yang akan dicapai dan berdasarkan prinsip-prinsip penilaian, dapat melaksanaan penilaian peserta didik secara profesional, terbuka, edukatif, efektif, efisien, dan sesuai dengan konteks sosial budaya; dan sekaligus dapat melaksanakan laporan hasil penilaian peserta didik secara objektif, akuntabel, dan informatif.

Penilaian pembelajaran seharusnya dilakukan secara komprehensif, mencakup semua ranah baik pengetahuan (knowledge), keterampilan (skill), maupun sikap (attitude). Penilaian juga seharusnya menekankan pada proses dan hasil pembelajaran. Instrumen yang dapat digunakan dalam penilaian dapat berupa tes dan non tes. (Ermawati \& Hidayat, 2017). Pada pelaksanaan kegiatan pengabdian, guru MGMP IPA dibekali dengan pengetahuan dan pemahaman bahwa dalam proses pembelajaran IPA di SMP hendaknya guru tidak hanya menekankan pada aspek kognitif saja, tetapi juga afektif. Selain itu juga diberikan contoh mengenai pelaksanaan penilaian autentik pada pembelajaran IPA.

Proses penilaian dalam pembelajaran diperlukan sebagai satu kesatuan yang tidak dapat dipisahkan pada kurikulum dan pembelajaran (Hyde, 2013). Implikasi pernyataan tersebut disesuaikan dengan kurikulum 2013, yaitu keberhasilan belajar peserta didik dalam mencapai standar kompetensi harus memuat aspek sikap, keterampilan dan pengetahuan (Ani, 2013). Pada setiap mata pelajaran, sebaiknya penilaian tidak hanya mengacu pada aspek pengetahuannya saja, tetapi juga keterampilan dan sikap. Oleh karena itu, penilaian autentik sangat penting diterapkan pada proses pembelajaran agar peserta didik dapat dibimbing untuk tidak hanya memiliki kemampuan di bidang pengetahuan saja, tetapi juga sikap.

Penilaian autentik diperlukan sebagai alat untuk mengukur kemampuan dalam tugas yang mewakili masalah dunia nyata (Frey \& Schmitt, 2007). Menurut Permendikbud Nomor 66 tahun 2013 menyebutkan bahwa penilaian autentik adalah penilaian yang komprehensif dan menyeluruh. sedangkan autentik menurut Frey, et al., (2012) sering digunakan sebagai tugas cerminan dari kenyataan pengetahuan yang dimiliki oleh peserta didik. 
Kegiatan dilakukan menjadi 4 bagian yaitu peserta diberikan prestes dan angket untuk mengetahui kemampuan awal dan kondisi tentaang penilaian autentik, kedua yaitu pengenalan penilaian autentik oleh dosen pelaksana. Materi disampaikan secara interaktif dengan bantuan media projector. Materi yang disampaikan pengertian penilaian autentik dan bentuk penilaian autentik. Ketiga, yaitu dilanjutkan bimbingan teknis penilaiaan autentik yaitu dengan memberikan contoh-contoh instrumen yang digunakan pada penilaian autentik dan dilanjutkan berdiskusi terhadap proses peniaian yang selama ini telah dilaksanakan sebagai bentuk refleksi. Terakhir, peserta diberikan postes untuk mengukur ketercapaian proses pembelajaran dan diberikan angket terhadap kegiatan pembelajaran yang digunakan sebagai sebagai evaluasi pemateri untuk tahapa selanjutnya.

Hasil kegiatan menunjukkan bahwa terjadi peningkatan pemahaman guru terhadap penilaian autentik. Selain itu respon peserta yang mengikuti kegiatan ini positif. Guru termotivasi dan antusias dalam melaksanakan penilain autentik. Selama ini hasil dari diskusi dengan guru peserta, penilaian terhadap siswa hanya berdasar aspek kognitif saja, setelah diadakannya kegiatan ini guru menjadi memahami dan diharapakan juga dapat menerapkan penilaian yang lebih mencerminkan kemampuan siswa dalam belajar yaitu tidak hanya aspek kognitif saja, tetapi juga spek afektif dan psikomotor.

\section{PENUTUP}

\section{Simpulan}

Berdasarkan data hasil pre tes dan postes pada pelaksanaan kegiatan dan analisis proses maka dapat disimpulkan bahwa kegiatan pengabdian masyarakat ini terbukti berhasil meningkatkan pengetahuan guru IPA Biologi Kabupaten Bogor. Penyapaian informasi terhadap penilaian autentik dapat diterima baik oleh guru MGMP IPA Kabupaten Bogor

\section{Saran}

Kegiatan pelaksanaan kegiatan mengenai sosialisasi tentang penilaian autentik diharapkan dapat dilaksanakan secara berkelanjutan, sehingga kemajuan pencapaian tujuan kegiatan dapat termonitor, dan dapat digunakan untuk melakukan perbaikan bila terdapat hambatan dalam pelaksanaan kegiatan pengenalan dan bimbinan teknis penilaian autentik.

\section{UCAPAN TERIMAKASIH}

Kegiatan Kepada Masyarakat ini terlaksana berkat bantuan dana dari BLU FMIPA Universitas Negeri Jakarta sesuai dengan surat perjanjian no. 41/spk pengabdian masyarakat/5.fmipa/2018 dan bantuan dari MGMP IPA Kabupaten Bogor, SMP Negeri 1 Cibinong dan Dinas Pendidikan dan Kebudayaan Kabupaten Bogor. 
Rizhal Hendi Ristanto, Refirman Djamahar

\section{DAFTAR PUSTAKA}

Afrianto, A. (2019). Challenges of Using Portfolio Assessment as an Alternative Assessment Method for Teaching English in Indonesian Schools. International Journal of Educational Best Practices, 1(2), 106-114. Doi: 10.31258/ijebp.v1n2.p106-114

Amin, N., Bain, \& Suryadi, A. (2016). Pelaksanaan Penilaian Autentik dalam Pembelajaran Sejarah Kurikulum 2013 di SMA Negeri 1 Purwareja Klampok Tahun Pelajaran 2015/2016. Indonesian Journal of History Education, 4(2), 1-6. Retrieved from https://journal.unnes.ac.id/sju/index.php/ijhe/article/view/2174

Astriyandi, A., Chotimah, U., \& Faisal, E. El. (2016). Kemampuan guru menerapkan penilaian autentik dalam pembelajaran ppkn. Jurnal Bhineka Tunggal Ika, 3(2), 187-198.

Delita, F. (2018). Penerapan Authentic Assesment Pada Mata Kuliah IPS Terpadu Semester Gasal Tahun Ajaran 2016/2017. Jurnal Geografi. Doi: 10.24114/jg.v9i2.6970

Djamahar, R., Ristanto, R. H., Sartono, N., Ichsan, I. Z., \& Muhlisin, A. (2018). CIRSA: Designing Instructional Kits to Empower 21st Century Skill. Educational Process: International Journal, 7(3), 200-208. Doi: 10.22521/edupij.2018.73.4

Frey, B. B., Schmitt, V. L., \& Allen, J. P. (2012). Defining Authentic Classroom Assessment - Practical Assessment, Research \&amp; Evaluation. Practical Assessment, Research \& Evaluation, 17(2), 1-18. Retrieved from http://pareonline.net/getvn.asp?v=17\&n=2

Hobma, S. O., Ram, P. M., Muijtjens, A. M. M., Grol, R. P. T. M., \& Van Der Vleuten, C. P. M. (2004). Setting a standard for performance assesment of doctor-patient communication in general practice. Medical Education. https://doi.org/10.1111/j.1365-2929.2004.01918.x

Jerez, O., Baloian, N., \& Zurita, G. (2017). Authentic Assesment between Peers in Online Courses with a Large Number of Students. In Proceedings - IEEE 17th International Conference on Advanced Learning Technologies, ICALT 2017. https://doi.org/10.1109/ICALT.2017.160

Komalasari, K. (2011). Kontribusi Pembelajaran Kontekstual untuk Pengembangan Kompetensi Kewarganegaraan Peserta Didik SMP di Jabar. Mimbar.

Kuntari, E. M. (2013). Pendidikan Abad 21 dan Imlementasinya Pada Pembelajaran di Sekolah. Artikel Kurikulum 2013 SMK.

Kusmana, S. (2017). Pengembangan literasi dalam kurikulum pendidikan dasar dan menengah. Diglosia, 1(1), 151-164.

Larkin, T. L. (2014). The Student Conference: A Model of Authentic Assessment. International Journal of Engineering Pedagogy (IJEP), 4(2), 36. https://doi.org/10.3991/ijep.v4i2.3445 
Lestari, N., Mertha, I. W., \& Kusmiyati, K. (2019). PROFIL ASSESSMEN AUTENTIK PADA GURU-GURU DI SMP NEGERI SE-KOTA MATARAM. Jurnal Penelitian Pendidikan IPA. https://doi.org/10.29303/jppipa.v5i1.186

Ngadip. (2010). Konsep Dan Jenis Penilaian Autentik (Authentic Assesment). E-Jurnal Dinas Pendidikan Kota Surabaya.

Nurjananto, N., \& Kusumo, E. (2015). Pengembangan Instrumen Penilaian Autentik Untuk Mengukur Kompetensi Peserta Didik Materi Senyawa Hidrokarbon. Jurnal Inovasi Pendidikan Kimia, 9(2), 1575-1585.

Plake, B. S., \& Impara, J. C. (1996). Theacher Assesement Literacy: What Do Teachers Now about Assesment. In Handbook of Classroom Assessment. https://doi.org/10.1016/B978-012554155-8/50005-3

Safitri, D., \& Oktavia, M. (2017). Implementasi penilaian autentik kurikulum 2013. Edukasi IPS, 1(1), 31-40.

Satrianawati. (2014). Assessment Pembelajaran dan Authentic Assessment Dalam Implementasi Kurikulum 2013. Seminar Nasional Evaluasi Pendidikan Tahun 2014 ISBN 978-602-14215-5-0.

Siswanto, J., Saptaningrum, E., Saefan, J., Patonah, S., \& Nuvitalia, D. (2015). Ibm penyusunan penilaian autentik bagi guru sekolah di ponpes darul fikri bawen. Jurnal E-Dimas (Educations-Pengabdian Kepada Masyarakat), 6(2), 72-78.

Sridharan, B., \& Mustard, J. (2016). Authentic Assessment Methods: A Practical Handbook for Teaching Staff Part-I, Deakin University., (January). https://doi.org/10.13140/RG.2.1.2358.7921

Swacker, D. (2003). Authentic Assesment Grades Standards. TCRecord.Org.

Wangid, M. N., Mustadi, A., Senen, A., \& Herianingtyas, N. L. R. (2018). The evaluation of authentic assessment implementation of Curriculum 2013 in Elementary School. Jurnal Penelitian Dan Evaluasi Pendidikan, 21(1), 104-115. https://doi.org/10.21831/pep.v21i1.15779

Zuriyani, E. (2010). Literasi Sains Dan Pendidikan. Jurnal Sains Dan Pendidikan, 13. 